\title{
O tempo aldeia: construindo uma nova prática pedagógica
}

Ribamar Ribeiro Júnior ${ }^{1}$, Laécio Rocha de $\mathrm{Sena}^{2}$, William Bruno Silva Araújo ${ }^{3}$

${ }^{1}$ Universidade Federal de Minas Gerais - UFMG. Faculdade de Filosofia e Ciências Humanas. Avenida Antônio Carlos, 6627. Belo Horizonte - MG. Brasil. ribaamr.sociologo@gmail.com. ${ }^{2}$ Universidade Federal do Sul e Sudeste do Pará - UNIFESSPA. ${ }^{3}$ Instituto Federal do Pará - IFPA.

RESUMO: Este trabalho busca dialogar com o pensamento descolonial na educação a partir da experiência do Curso Técnico em Agroecologia do Campus Rural de Marabá, do Instituto Federal do Pará. Neste curso o itinerário formativo é constituído por dois tempos de estudo: o Tempo Escola e o Tempo Aldeia, caracterizado como "alternância pedagógica". Tal lógica parte do estudo da realidade "concreta", possibilitando aos educandos articulação dos conhecimentos tradicionais e os técnico-científicos relacionados às dimensões políticas, históricas, naturais. Nossa estratégia pedagógica adotada no CTAI se aproxima em parte da proposta de educação descolonial e o tempo aldeia se mostrou central na estratégia de se pensar e repensar formas de educação "outras" aquelas da modernidade.

Palavras-chave: Agroecologia, Alternância, Interculturalidade, Currículo. 


\title{
The time village: building a new pedagogical practice
}

\begin{abstract}
This work seeks to dialogue with the decolonial thinking in education from the experience of the Technical Course in Agroecology of the Rural Campus of Marabá, Federal Institute of Pará. In this course the formative itinerary is constituted by two study times: Time School and Time Village, characterized as "pedagogic alternation". This logic is part of the study of "concrete" reality, enabling students to articulate traditional and technical-scientific knowledge related to political, historical, and natural dimensions. Our pedagogical strategy adopted in the CTAI approximates in part the proposal of decolonial education and the village time was central in the strategy of thinking and rethinking forms of education "other" those of modernity.
\end{abstract}

Keywords: Agroecology, Alternation, Interculturality, Curriculum. 


\section{El tiempo aldea: construyendo una nueva práctica pedagógica}

RESUMEN: Este trabajo busca dialogar con el pensamiento descolonial en la educación a partir de la experiencia del Curso Técnico en Agroecología del Campus Rural de Marabá, del Instituto Federal de Pará. En este curso el itinerario formativo está constituido por dos tiempos de estudio: el Tiempo Escuela y el Tiempo Pueblo, caracterizado como "alternancia pedagógica". Tal lógica parte del estudio de la realidad "concreta", posibilitando a los educandos articulación de los conocimientos tradicionales y los técnico-científicos relacionados a las dimensiones políticas, históricas, naturales. Nuestra estrategia pedagógica adoptada en el CTAI se aproxima en parte de la propuesta de educación descolonial y el tiempo poblacional se mostró central en la estrategia de pensar y repensar formas de educación "otras" aquellas de la modernidad.

Palabras clave: Agroecología, Alternancia, La Interculturalidad, Currículo. 


\section{Introdução}

Este trabalho resulta da vivência e pesquisa dos autores sobre as práticas de ensino no Curso Técnico em Agroecologia Integrado ao Ensino Médio dos Povos Indígenas do Sudeste Paraense - CTAI, do Instituto Federal do Pará - IFPA, Campus Rural de Marabá - CRMB. O CTAI pode ser considerado desdobramento da iniciativa e disposição do CRMB em dialogar com a diversidade sociocultural da região de sua abrangência, o Sudeste Paraense. Neste cenário, o CRMB iniciou, a partir de 2009, um diálogo constante com os povos Assurini, Atikum, Parkatêjê, Akrãtikatêjê, Aikewara-Suruí, Amanayé, Guarani e Guajajara, bem como com as instituições que já atuavam junto a estes povos, como CIMI e UFPA em vista a conhecer e acolher as suas demandas educacionais. No quadro abaixo apresentamos a composição dos integrantes do curso por aldeia e povos.

Quadro I: Composição do número de alunos por aldeia/povo.

\begin{tabular}{|l|l|l|l|}
\hline $\begin{array}{l}\text { POVOS } \\
\text { INDÍGENAS }\end{array}$ & ALDEIAS & MUNICÍPIOS & $\begin{array}{l}\mathbf{N}^{\mathbf{0}} \mathbf{\text { DE}} \\
\text { ALUNOS }\end{array}$ \\
\hline Assuriní & Trocará & Tucuruí & 02 \\
\hline \multirow{2}{*}{ Amanayé } & Barreirinha & Paragominas & 05 \\
\cline { 2 - 4 } & Araradewa & Goianésia & 01 \\
\hline Atikum & Ororobá & Itupiranga & 04 \\
\hline Guarani & Nova Jacundá & Jacundá & 02 \\
\hline Guajajara & Guajanaíra & Itupiranga & 09 \\
\hline Parkatêjê & Kupejipôkti & Bom Jesus do Tocantins & 05 \\
\hline Akrãtikatêjê & Akrãti & & 05 \\
\hline \multirow{2}{*}{ Suruí } & Itahí & São Geraldo do Araguaia & 03 \\
\cline { 2 - 4 } & Sororó & & 37 \\
\hline
\end{tabular}

Fonte: Arquivos da coordenação do CTAI (2012).

Desse diálogo de mais de dois anos de construção coletiva foi concebido o CTAI, como uma experiência pioneira no âmbito dos Institutos Federais - Ifs do
Brasil. O curso está inserido no Eixo Tecnológico Recursos Naturais do catálogo de Cursos Técnicos do Ministério da Educação - MEC e desde sua 
concepção expressou como uma experiência desafiadora assumida.

A concepção do curso tomou como base os princípios da participação efetiva e diálogo verdadeiro preconizados pelo CRMB (PPP, 2010). Por turno, herdou o anseio do CRMB em ofertar uma educação comprometida com a sustentabilidade dos povos do campo de sua área de abrangência. Também considerou a "crítica ao "processo colonial" na educação da modernidade, cujos principais desdobramentos se expressam na negação da diversidade, na folclorização das sabedorias e epistemologias 'outras' aquelas ocidentais modernas" (Santos, 2005, p. 26-27).

Neste cenário, buscou-se com esta pesquisa analisar a experiência do CTAI à luz das teorias descoloniais, desde $\mathrm{o}$ processo de concepção e efetivação e desenvolvimento do curso, as interfaces entre avanços e limites da experiência e suas contribuições para se pensar e repensar novas propostas de se construir processos educativos formais "outros" aqueles hegemônicos na modernidade.

Esta pesquisa contou com a leitura dos relatórios produzidos pelos educandos a partir do Tempo Aldeia, com base nos Plano de Estudo, Pesquisa e Trabalho PEPT. O PEPT é uma ferramenta metodológica utilizada para orientar a pesquisa durante o Tempo Aldeia, normalmente organizado na forma de um roteiro, com as questões previamente discutidas e encaminhadas aos educandos no último dia de aula de cada Tempo Escola. Essas orientações dirigidas tinham como objetivo assegurar o momento de vivência da pesquisa nas aldeias, onde os educandos no primeiro momento reuniam a comunidade para socializar as atividades escolares e apresentar o PEPT, garantindo assim, a participação da comunidade no processo formativo.

Nossa intenção é argumentar com os autores descoloniais, (Mignolo, 2008 \& Quijano, 1997); as possibilidades de rompimentos de paradigmas pedagógicos disciplinares no processo de produção de conhecimento, para tanto Mignolo (2008, p. 04) afirma que “a opção descolonial significa, entre outras coisas, aprender a desaprender". Desta forma, a experiência vivenciada no curso em análise nos permite construir conexões de uma prática pedagógica que associa um processo de aprendizagem de forma relacional com os processos cotidiano dos educandos, pautado nas suas experiências desenvolvidas nas aldeias.

O percurso formativo em análise faz parte de um processo que chamamos no curso de alternância pedagógica, dispondo de instrumentos metodológicos, como o 
plano de estudo; Diagnóstico Sociocultural e Ambiental das Aldeias e uma organização didática constituída em dois momentos: o período das atividades escolares e o da pesquisa na aldeia. Todavia, o funcionamento do curso se deu efetivamente pelo envolvimento dos alunos em atividades de pesquisa, que relacione no fazer de suas ações na aldeia e problematize questões relacionadas a ela, é neste contexto que há uma formação teórica e prática dos educandos.

Neste sentido, o I Ciclo pedagógico do curso teve como foco a realização do diagnóstico sociocultural das aldeias, os primeiros PEPTs orientavam os educandos a trazer informações sobre a história da comunidade, da cultura, dos saberes e práticas dos indígenas. No retorno á escola, a primeira atividade do Tempo Escola era articulada pela disciplina de "Metodologia da Pesquisa", cujas atividades se davam com a socialização dos dados pelos educandos por aldeia e no momento posterior a sistematização em forma de relatório. Com base nestas informações, os professores de outras áreas de conhecimento tinham acesso para elaboração de seus planos de aula, baseado na realidade dessas comunidades.

Vale ressaltar que o Tempo Aldeia é contabilizado na carga horária, onde as disciplinas envolvidas destinavam cerca de
$30 \%$ de carga horária já prevista na matriz curricular do curso, e com acompanhamento de educadores nas aldeias em alguns momentos, pois estes contribuíam com os educandos no processo de socialização das atividades realizadas no Tempo Escola, tendo reuniões com as lideranças indígenas para ouvir as demandas e tratar de assuntos relacionados ao curso. Portanto, é nesta vivência que os diferentes conteúdos vão sendo colocados em prática.

Quando se observa, por exemplo, que no II Ciclo do curso tem como objetivo a caracterização dos agroecossistemas das aldeias e proposições para o manejo e gestão dos recursos naturais, o principal elemento articulador foi o desenvolvimento das ações para implantação dos experimentos socioprodutivos, que foi gerando as discussões e dados para o percurso formativo, conjugando assim, em diferentes experiências para prática de ensino dos educadores e com princípios pedagógicos para formação dos técnicos que terão condições de assumir em suas aldeias o protagonismo dos projetos.

A pesquisa bibliográfica e documental propiciou o desenvolvimento da investigação e favoreceu a análise das informações coletadas. Os produtos das pesquisas como Mapas das Aldeias, 
Calendário Agrocultural, Livro de História de Vida e o processo de implantação dos projetos socioprodutivos, demonstraram que foi superado com o acúmulo obtido tanto pelos professores como pelos estudantes ao longo do curso.

\section{Conhecimento científico e colonização do saber: regulação versus emancipação}

$\mathrm{Na}$ perspectiva da colonialidade do poder, reconhecendo a separação epistemologicamente operada entre o sujeito e objeto, Mignolo (2003) demonstra como a ciência moderna esteve atrelada ao projeto de colonialidade instaurado na modernidade, demarcando aquele polo a ser conhecido (os povos "sem" história e cultura, como por exemplo, os indoamericanos) e o sujeito cognoscente, sujeito do conhecimento. Nessa imbricada rede de consolidação do projeto modernocolonial há uma relação muito intrínseca entre saber e poder.

$\mathrm{Na}$ esteira dessa discussão, afirma ser indispensável firmar a necessidade de não só reconhecer uma fronteira entre esses dois polos em questão, mas também a necessidade de construção de um novo conhecimento, uma nova ciência, construída, por sua vez, a partir da exterioridade.
Falar em colonialidade do poder significa reconhecer que a consolidação do conhecimento científico como o conhecimento verdadeiro se dá dentro de um processo marcado por uma diferença colonial, onde não só uma perspectiva predomina como também outros saberes são subalternizados.

O pensamento limitar epistemologicamente propõe um novo lócus de enunciação, às margens. Mais que isso, pressupõe uma nova linguagem. Leva-os a entender que é preciso colocar em questão as relações de força que subalternizaram outros saberes, em detrimento de um só conhecimento.

Dessa forma, a colonialidade do poder, como nos mostra Quijano (1997), pressupõe e se dá a partir de pelo menos quatro aspectos: i) a classificação e reclassificação da população do planeta, tendo a noção de cultural como algo estruturante; ii) a articulação e administração dessa classificação através de instituições (tais como, o Estado, universidades, igrejas, etc.); iii) a definição de espaços adequados para esses objetivos e iv) "uma perspectiva epistemológica para articular o sentido e o perfil da nova matriz de poder e a partir da qual canalizar a nova produção do conhecimento" (p. 41)

A expansão ocidental que se deu a partir do século XVI, como nos mostra 
Mignolo (2003), foi também a "expansão de formas hegemônicas de conhecimento", contribuindo assim para a subalternização de outras formas de conhecimento existentes nas terras a serem "conquistadas".

A colonialidade é a modernidade vista por sua margem, pelo outro lado da fronteira. Segundo Mignolo:

a colonialidade traz para o primeiro plano a coexistência e interseção tanto dos colonialismos modernos quanto das modernidades coloniais (e, obviamente, a multiplicação das historias locais que substituem a história mundial ou universal), na perspectiva dos povos e historia locais quem têm de confrontar o colonialismo moderno (Mignolo, 2003, p. 47).

Para Lander (2005) o pensamento científico moderno opera de forma hábil no sentido de produzir uma "naturalização das relações sociais". Nessa perspectiva, os sujeitos são compelidos a acreditarem que "a sociedade liberal constitui ... não apenas a ordem social desejável, mas também a única possível" (Lander, 2005, p. 08). Para o autor, as ciências sociais contribuíram sobremaneira nesse processo, levando à hegemonização da narrativa neoliberal, interditando outros discursos, outros conhecimentos. Assim, segundo Lander:

$\mathrm{O}$ processo que culminou com a consolidação das relações de produção capitalistas e do modo de vida liberal, até que estas adquirissem o caráter de formas naturais de vida social, teve simultaneamente uma dimensão colonial/imperial de conquista e/ou submissão de outros continentes e territórios por parte das potências européias, e uma encarniçada luta civilizatória no interior do território europeu na qual finalmente acabouse impondo a hegemonia do projeto liberal. (Lander, 2005, p. 12).

São nesse cenário que se constituem as ciências sociais, estando, portanto atrelada o seu desenvolvimento ao advento da modernidade e a sua face colonial. Nesse sentido, como bem nos afirma Mignolo (2003) não se pode falar de modernidade sem considerar a colonialidade como algo que lhe é constitutivo, isto é, modernidade e colonialidade são partes do mesmo processo.

Ainda acerca da relação entre as ciências sociais e sua importância na consolidação e naturalização da sociedade neoliberal vale destacar que, segundo Lander (2005, p 13), dois aspectos fundamentais: primeiramente, "a suposição da existência de um metarrelato universal que leva a todas as culturas e a todos os povos do primitivo e tradicional até o moderno". Dessa forma, institui-se a sociedade liberal europeia como norma, padrão, devendo as demais sociedades ser niveladas/classificadas tomando-a como 
referência. O segundo aspecto é que, "as formas do conhecimento desenvolvidas para a compreensão dessa sociedade [a europeia] se converteram nas únicas formas válidas, objetivas e universais de conhecimento".

O pensamento ocidental moderno é um pensamento abissal. Ele consiste num sistema de distinções visíveis e invisíveis. As invisíveis constituem o fundamento das visíveis e são estabelecidas através de linhas radicais que dividem a realidade social em dois universos, o universo "deste lado da linha" e o universo do "outro lado da linha". A divisão é tal que o outro lado da linha desaparece como realidade, se converte em inexistente (Santos, 2010, p. 29).

Segundo Santos (2010) o que mais caracteriza o pensamento abissal é justamente a impossibilidade de coexistência entre esses dois lados da linha, sendo que o lado de lá é invisibilizado, tornado o outro do conhecimento ocidental e, portanto, tendo os seus sujeito e saberes estigmatizados, menosprezados e desta forma, justificando a ação colonizadora e reguladora do Estado moderno. Essa colonização se dá também na perspectiva epistemológica, uma vez que os saberes e práticas do sujeito do lado de lá da linha são negados, eclipsados, em nome de uma única forma de conhecimento: a ciência. Esta, por sua vez, se mostrou ao longo da história como um conhecimento cada vez mais regulador.

É mister ressaltar, conforme Santos (2010), que cada vez mais essa linha abissal tem sido colocada em xeque por esses sujeitos subalternizados. Segundo o autor, "o outro lado da linha se ergueu contra a exclusão social, as populações que haviam sido submetidas ao paradigma da apropriação/violência se organizam e clamam pelo direito de serem incluídas no paradigma" (Santos, 2010, p. 37-38).

A ação política desses sujeitos subalternizados tem forçado a academia e o próprio Estado a se repensar e reestruturar as suas políticas públicas educacionais. Outros sujeitos, outras pedagogias. De acordo com Arroyo (2014), os coletivos populares trazem para as teorias e práticas educativas que os pensem produzidos dentro de uma relação marcada por dominação/subalternização/opressão. São várias experiências dessas que tem acontecido no Brasil nos últimos anos, com avanço de discussões que estão em torno de uma maior participação destes "sujeitos".

A resistência política desses "sujeitos" subalternizados, invisibilizados, representa também uma resistência epistemológica e, com isso, uma pressão a fim de por fim às linhas abissais (Arroyo, 
2010; Santos, 2010). Em suma, é no bojo dessa compreensão acerca da relação tensa entre uma racionalidade reguladora - que marca a ciência moderna $-\mathrm{e}$ a racionalidade emancipadora, com vistas à promoção da igualdade social, que a acadêmica é hoje um campo de disputa na perspectiva de Bourdieu (2005) - entre diferentes saberes. O diálogo entre diferentes saberes é fundamental na construção de uma proposta educacional com objetivo de promover a igualdade social e emancipação desses sujeitos historicamente subalternizados.

\section{Construção participativa e o diálogo entre diferentes saberes}

A construção da proposta do CTAI teve início 2009 pelo Campus Rural de Marabá, do Instituto Federal de Educação, Ciência e Tecnologia do Pará, pautando-se, sobretudo, pelo diálogo com as lideranças e sábios de cada aldeia, em vista de conhecimento de sua história, projetos societários e desafios dos mais diversos, tais como aqueles voltados para as atividades produtivas, gestão do território e fortalecimento da cultura e identidades de cada povo.

Dessa forma, o processo de construção seguiu os seguintes passos: o primeiro a realização de visitas às aldeias, com vistas à construção de um breve diagnóstico sócio cultural e agroambiental das comunidades indígenas nas diversas áreas onde havia demanda. Foram visitados os povos: Aikewara, Atikum, Guajajara, Guarani, Amanayé, Akrãtikatêjê, Parkatêjê e Assurini do Trocará, totalizando 9 povos e 12 aldeias.

Após as visitas foi realizado um seminário com o objetivo de apresentar e discutir o diagnóstico preliminar com vistas ao processo de implantação do curso. Esse seminário contou com a presença de instituições governamentais, não governamentais, representantes $\mathrm{e}$ lideranças de vários povos indígenas. Foi um momento decisivo para se ter a clareza de optar por um curso técnico em agroecologia, pautando-se pelo diálogo e respeito aos modos de vida de cada povo.

Esse diálogo constante com as lideranças indígenas e os sábios de cada povo foram fundamentais, uma vez que proporcionou novos momentos que ajudaram a aprofundar essa etapa de construção, garantindo uma proposta de curso que dialogasse com os anseios e desafios de cada povo. Em 2010, ocorreu a restituição do diagnóstico nas aldeias, com detalhamento de demandas apresentadas pelos indígenas, e a construção do Projeto Político Pedagógico do curso Técnico em Agroecologia integrado ao Ensino Médio. 
$\mathrm{O}$ curso tem como objetivo a formação de jovens indígenas do sudeste paraense, na perspectiva intercultural do diálogo de saberes/práticas tradicionais e conhecimentos técnico-científicos e da articulação de formação humanista e profissional, através de diferentes práticas, tempos e espaços pedagógicos, visando contribuir para a segurança alimentar, a gestão territorial e ambiental e com os projetos societários de cada povo.

Ainda em 2010, foi realizada uma formação dos Educadores do Campus Rural de Marabá do Instituto Federal de Educação do Pará CRMB/IFPA sobre Educação Escolar Indígena. Essa formação permitiu que o quadro de professores tivesse acesso aos processos educativos dos indígenas, tendo em vista que houve uma participação dos professores das aldeias e lideranças indígenas.

Somente no ano de 2011, com a realização do II Seminário dos Povos Indígenas do Sudeste Paraense, cujo objetivo foi concluir o ementário das disciplinas, elaborar as diretrizes de funcionamento do curso, e discutir a metodologia do processo de seleção dos candidatos ao curso, que ocorreu os encaminhamentos finais para o inicio do curso. É importante ressaltar, que o ponto chave do segundo seminário foi aprovar o documento oficial redigido e assinado pelos presentes que desencadeou no processo seletivo, estabelecendo duas etapas, sendo que todas seriam realizadas nas aldeias dos povos presentes no seminário. Uma etapa constituía-se de uma roda de conversa, onde tinha uma banca composta por membros do IFPA $\mathrm{e}$ instituições parceiras junto com os candidatos ao curso, à comunidade e as lideranças indígenas. A outra, os candidatos realizaram uma produção de texto, trazendo vários elementos, como a historia, cultura e tradições do seu povo, como também alguns problemas e desafios da aldeia. Nesse caso, ressaltam-se os desafios de ordem técnico-produtiva, como também de políticas públicas.

Esses elementos levantados nas aldeias, durante o processo seletivo, foram importantes para o planejamento das atividades ao longo do percurso formativo do curso, numa perspectiva de uma educação escolar indígena que dialogue com a realidade do educando. Neste sentido, foram elencados os desafios da construção da proposta de integração curricular, com um currículo pautado não somente em elementos teóricos, mas concretos, partindo da realidade e necessidade dos sujeitos demandantes, integrando não somente partes, conforme Araújo e Ribeiro Junior (2016). 
Ressaltamos o grande desafio de refletir a região sudeste do Pará, como um importante território na Amazônia Oriental, cuja população indígena está distribuída em várias áreas. Elas compõem uma multiplicidade de situações, que se refere à extensão de suas terras, gestão dos territórios e a socioeconomia, e às questões de sua organização social. Na questão do território, existem povos que estão em Terras Indígenas já homologadas com seus territórios reconhecidos e outros que se encontram como assentados da reforma agrária são grupos que migraram para região sudeste do Pará, vindos de outras regiões do Brasil. Estes últimos, sobretudo na década de noventa, porém todos sob impactos de grandes projetos que atingiram, diretamente, seus territórios, suas condições de vida, levando a constituir estratégias como opção de reproduzir sua existência. Neste contexto, estão os “Gavião" da Terra Indígena Mãe Maria localizados no município de Bom Jesus do Tocantins no sudeste paraense, divididos em três grupos locais: os Parkatêjê, Kyikatêjê e os Akrãtikatêjê, e também os Aikewara, Guajajara, Atikum, Amanayé, Guarani, Assurini, todos na região sudeste do Pará, onde tiveram seus territórios impactados por grandes empreendimentos.
Os Aikewara tiverem o contato com a sociedade nacional, como nos mostra Laraia e Da Matta (1967) durante o período de exploração extrativa da castanha, ainda na década de 1950, e na década de 1970, com a Guerrilha do Araguaia, tiveram seu território e sua aldeia invadida pelo exército brasileiro, a sua terra sendo cortada por estradas abertas pelos militares, entre outros fatores. A atuação do exército na terra indígena Sororó durante a Guerrilha do Araguaia é um episodio bastante traumático na memoria deste povo indígena.

Os povos Guajajara, Atikum e Guarani são oriundos de outras regiões do país, e chegam à região muito recentemente. Ambos sofrem com as pressões das grandes fazendas que lhes avizinham e com o seu reduzido território. Os Atikum e Guajajaras, por exemplo, vivem em diferentes áreas de assentamento de Reforma Agrária, no município de Itupiranga. Enquanto os Guajajaras são naturais do Maranhão, os Atikum migraram do estado de Pernambuco. Já o povo Guarani vive numa terra indígena, no município de Jacundá, porém numa área pequena ainda em fase de expansão.

Do ponto de vista das atividades sócio produtivas realizadas nas aldeias, o relatório apontou para os seguintes tipo de cultivo e territórios de produção (CRMB, 
2010), os quais sejam: cultivo de roçados e produção de farinha, cultivo de sítios e pomares, horticultura, pequenos animais, coleta de fruto e caça, criação de gado e pesca. $\mathrm{O}$ beneficiamento e a comercialização da produção era uma demanda comum a todas as comunidades indígenas. $\mathrm{O}$ artesanato é uma atividade realizada na maioria das aldeias, no entanto essa atividade se encontra ameaçada, tendo em vista a diminuição crescente dos recursos naturais.

É frente a esse cenário, e esses desafios vivenciados pelos povos indígenas da região sudeste do Pará que foi pensado e construído, de forma participativa e dialogada, o Curso Técnico de Agroecologia. Para potencializar o diálogo entre as demandas dos povos indígenas e os saberes científicos discutidos no âmbito do curso foi fundamental a interface entre o conhecimento científico e os saberes tradicionalmente construídos por esses povos indígenas, operacionalizando assim uma descolonização do currículo escolar e uma ecologia dos saberes (Santos, 2010).

Para proporcionar esse espaço, duas propostas do curso foram executadas com diferentes estratégias pedagógicas, dentre as quais se podem citar a alternância pedagógica e o PEPT (Plano de Estudo, Pesquisa e Trabalho). Com vistas à promoção de uma educação intercultural, a alternância pedagógica, conforme afirma o PPC do curso, busca o "desenvolvimento de processos formativos integrados a articulação entre as áreas do conhecimento (humanidades, linguagens, exatas e naturais), saberes tradicionais e científicos, formação humana e profissional, diferentes práticas, tempos e espaços pedagógicos" (CRMB, 2010, p. 36, grifos nossos).

Nessa alternância pedagógica, dois espaços formativos importantes são 0 tempo-espaço aldeia e o tempo-espaço escola. O primeiro é "se caracteriza por ser o momento de vivência, pesquisa, experimentação e ressignificação dos conteúdos escolares e dos saberes/práticas tradicionais dos próprios indígenas" (CRMB, 2010, p. 37). Esse tempo-espaço formativo é prensado de forma articulada com o tempo-espaço escola, pois é nele que "se organiza como um momento de distanciamento do cotidiano/contexto de origem, visando desencadear um processo de escolarização que se faça como momento de reflexão sobre a vida na família/comunidade, a produção e a realidade social mais ampla". Articulação entre esses diferentes espaços formativo, conforme já afirmamos é de suma importância para o diálogo intercultural.

É nesta perspectiva que o PEPT cumpre um papel enquanto instrumento pedagógico articulador entre a construção 
do conhecimento na escola e a pesquisa realizada nas aldeias. Aqui a pesquisa articula a investigação com a práxis.

De acordo com Freire:

\begin{abstract}
Simplesmente, não posso conhecer a realidade de que participam a não ser com eles como sujeitos também deste conhecimento que, sendo para eles, um conhecimento do conhecimento anterior (o que se dá ao nível de sua experiência quotidiana) se torna um novo conhecimento (Freire, 1982, p. $35)$.
\end{abstract}

Desse modo, empreender uma pesquisa nessa perspectiva significa reconhecer os saberes e práticas às quais esses sujeitos são portadores, bem como o modo como os mesmo significam sua prática cotidiana. Mais que isso, ao adotarmos essa postura, como nos assevera Borda (1982, p. 52) "soluciona-se não apenas o problema de 'para quem' este estudo é feito, mas também o da incorporação do cientista ao meio em que ele deve atuar”. É essa inserção do pesquisador na realidade a ser pesquisada, e sua disposição a dialogar com esses sujeitos, reconhecendo-os não como objetos, mas enquanto sujeitos ativos do pesquisar, que potencializa uma pesquisaação transformadora. De acordo com Borda,

A potencialidade da pesquisa participante está precisamente no seu deslocamento proposital das universidades para o campo concreto da realidade. Esse tipo de pesquisa modifica basicamente a estrutura acadêmica clássica na medida em que reduz as diferenças entre objeto e sujeito de estudo. Ela induz os eruditos a descer das torres de marfim e a se sujeitarem ao juíz das comunidades em que vivem e trabalham, em vez de fazerem avaliações de doutores e catedráticos (Borda, 1982, p. 60).

Frente às questões colocadas aqui, partiremos agora para uma reflexão acerca do PEPT e da articulação entre os diferentes tempos-espaços formativos para o diálogo entre os saberes científicos e aqueles tradicionalmente construídos nas comunidades indígenas, tendo em vista os desafios dessas comunidades.

As contribuições da pesquisa do Tempo Aldeia possibilitaram um exercício de interculturalidade entre a escola e os povos indígenas integrantes do curso. Os conhecimentos trazidos pelos educandos foram se integrando aos conteúdos das disciplinas por meio dos dados socializados e sistematizados. O livro de História de Vida e Calendário Agrocultural proporcionou de uma forma geral uma integração das etnias, onde os jovens estudantes passaram a conhecer seus parentes que ainda não tinham muito conhecimento, apesar de todos os grupos pertencerem à mesorregião do sudeste paraense. 
Para tanto, vale ressaltar a importância da troca de experiência com estes conhecimentos, levando em consideração os sentidos atribuídos à formação. Para tanto, Silva (2012, p. 169) reflete sobre os "processos de trabalho, modos de vida e culturas especificas" como representações de escola e interação com os indivíduos. Destacam-se, neste sentido os diferentes objetivos que estão atribuídos a este processo de alternância, "Seja como estratégia de inclusão escolar, cuja ênfase era a permanência do aluno na atividade familiar produtiva, seja como estratégia de qualificação profissional do jovem, cuja ênfase era o subsídio técnico à agricultura" (Silva, 2012, p. 172).

Essa singularidade é conferida com os jovens indígenas, sobretudo do ponto de vista do envolvimento nas atividades práticas encaminhadas para serem associadas as suas realidades. O que nos leva a refletir sobre os processos de aprendizagem a partir da abordagem de integração curricular dos conteúdos que foram sendo trabalhados com evidencia a uma prática.

Com essa dinâmica os conteúdos encontram-se em permanente relação, sempre se complementando e articulados, e como se trata de nove etnias, há um significado muito grande nesta relação de práticas e saberes dessas populações dialogando com novas aprendizagens, o que considero como aspecto diferenciador, o propósito que tem de desenvolver praticas agroecológicas e trocas essas experiências com o saber institucional.

Silva (2012, p. 29) “pressupõe a existência de um vai e vem necessário para permitir ao saber formalizado se confrontar com a prática e ao saber prático se formalizar", é neste confronto que as contribuições dessa prática educativa do Curso de Agroecologia do Campus Rural de Marabá, tem se evidenciado.

Para um curso de Agroecologia essa experiência em alternância, dando relevância ao período que os estudantes ficam na aldeia com atividades, passa a convergir com uma reflexão às condições adotada, prevalecendo uma visão critica e com práticas concretas de um ensino técnico que leva em consideração o diálogo com o conhecimento das populações indígenas. Sobretudo, rompendo com a lógica das disciplinas compartimentadas por conteúdos fora da realidade.

Nos relatórios produzidos pelos estudantes aborda os limites que encontram com a comunidade quando são levadas tarefas que essa comunidade rejeita. Em um destes documentos assinados por estudante Atikum, ele resume como a sua comunidade não deu andamento a proposta 
realizada por técnicos da Companhia Nacional de Abastecimento (CONAB), durante uma oficina organizada pela coordenação do curso para constar como atividade de Tempo Aldeia, que seria a elaboração de um projeto para ser submetido ao Programa de Aquisição de Alimentos (PAA).

Chegamos a fazer uma reunião com as lideranças e comunidade onde teve família que se interessou em fazer o projeto - como não tinha conhecimento não fizeram, por mais que nós explicamos, o cacique aconselhou que para fazer o projeto tinha que ter um conhecimento suficiente (André Atikum - Relatório de Visita de Campo).

Neste caso o esforço feito foi de capacitar os jovens estudantes para o processo de elaboração de projetos. A deficiência no momento em que o órgão do governo possibilitou a oportunidade de uma inserção das comunidades indígenas em fornecer alimento para o Campus Rural de Marabá, através do PAA, porém, foram esbarradas nas limitações técnicas. Pois, consta que na maioria das comunidades havia os produtos para serem comercializados.

O dialogo e interação entre as áreas de conhecimento se apresenta como desafios, por ser uma proposta inovadora e isso exige disponibilidade para compreender as problemáticas elencadas pelos alunos, que na maioria das vezes é trazida como porta-vozes das comunidades elencadas. Portanto, percebe-se que a proposta pedagógica do Campus Rural de Marabá, está clara no sentido de um projeto de educação em construção, e, que a educação profissional tem objetivo de atender os povos do campo. Envolvendo a dimensão da interdisciplinaridade. É importante ressaltar que essa formação técnica e tecnológica associada à interdisciplinaridade, não pode ser vista como um modismo. Para isso Stuani (2010) destaca que:

trabalhar interdisciplinarmente, requer uma mudança de postura frente ao conhecimento e ao ato educativo; exige busca constante por novos conhecimentos e um maior diálogo entre as áreas do conhecimento. Portanto, pensar o conhecimento em sua totalidade, envolve romper com as barreiras que individualizam as disciplinas, buscando perceber as interfaces que ligam os diferentes saberes na compreensão dos fenômenos estudados. Diria que o sentido do interdisciplinar está na contribuição das áreas do conhecimento, no entendimento de um objeto de estudo comum, desvelando as várias dimensões que o envolvem, dando um sentido de totalidade (Stuani, 2010, p. 78).

Ademais, configura-se que o que foi pensado, construído e vivenciado neste curso técnico em agroecologia, não pode ser compreendido apenas como uma 
experiência isolada, pois a forte participação de outros sujeitos em outras etapas de formação tem colocado em destaque o fato de o Tempo Aldeia, ou Tempo Comunidade (para os cursos regulares da instituição como Técnico em Agropecuária Licenciatura em Educação do Campo), ser um importante instrumento metodológico de pesquisa, ensino e extensão, ao mesmo tempo em que são colocadas na prática as ações que são desenvolvidas neste período.

\section{Conclusões}

Na perspectiva de uma construção de uma proposta de curso que dialogasse e respondesse aos desafios da mais diversa ordem enfrentados pelas comunidades indígenas da região sudeste do Pará, foi fundamental um diálogo intercultural entre os saberes dos povos indígenas da região e os conhecimentos construídos no âmbito da academia. Isso por sua, levou-nos a repensar o lugar do próprio conhecimento cientifico na sociedade ocidental, vendo-o numa perspectiva política, alinhada a um processo moderno/colonial de supressão de outros saberes e práticas que existem dentro de uma diversidade e são desconsideradas em nome desse processo. Para tanto, foi fundamental o diálogo com a teoria descolonial, a qual nos faz refletir profundamente sobre experiências como esta.

O objetivo deste trabalho em buscar o diálogo e as contribuições desse processo de formação integrada nos apresenta uma análise visando compreender os propósitos da alternância num curso técnico, onde jovens de diferentes etnias foram possibilitados aos domínios de conhecimento técnico-científico combinados com suas práticas desenvolvidas nas suas comunidades, buscando compreender as lógicas e lugares diante dos impactos que essas populações têm sofrido frente aos grandes projetos na região sudeste paraense.

Portanto, a experiência estudada figura no cenário de inserção de realidades socioeconômicas, culturais e ambientais protagonizadas por sujeitos que vivenciam nestes territórios uma dinâmica diversificada, onde o curso passa a ser um espaço a mais de valorização e vivência da identidade étnica. O que se aprende e ensina vai ganhando outro significado, uma vez que podemos dialogar com códigos conhecidos e dominados por indígenas.

Constata-se que o processo de alternância, mais precisamente o Tempo Aldeia, foi fundamental para assegurar o funcionamento do curso e garantir de fato que a proposta pedagógica fosse validada. 
Um dos motivos dessa importância está nas constantes mobilidades feitas pelos estudantes. A necessidade de estarem perto da família, às responsabilidades atribuídas pelas lideranças a estes jovens e o compromisso de ter uma boa formação, mesmo considerando todas as dificuldades de deslocamentos das aldeias para a escola.

Conciliar os dois universos de aprendizados colocam os professores num conjunto de circunstâncias, do fazer, do ensinar e aprender. Isso quebra velhos paradigmas de uma educação tradicional, que apenas reproduz. Para um curso técnico, é um ato de construir currículo praticando um ensino diferenciado.

\section{Referências}

Araújo, W., \& Ribeiro Jr, R. (2016). Convergências entre a pesquisa agroecológica e a pesquisa socioantropológica e contribuições dessas abordagens de pesquisa na construção curricular. Revista Lugares de Educação, 6(12), 139-157.

Arroyo, M. (2014). Outros sujeitos, outras pedagogias. Petrópolis: Vozes.

Borda, O. F. (Org.). (1982). Aspectos teóricos da pesquisa participante: considerações sobre o significado $e \quad o$ papel das ciências na participação popular. São Paulo: Brasiliense.

Bourdieu, P. (2005). Economia das trocas simbólicas. São Paulo: Editora Perspectiva.
Freire, P. (Org.). (1982). Criando Métodos de Pesquisa Alternativa: aprendendo a fazê-la melhor através da ação. São Paulo: Brasiliense.

IFPA/CRMB. (2010). Projeto Político Pedagógico do Campus Rural de Marabá.

IFPA/CRMB. (2011). Projeto Político Pedagógico: Curso Técnico em Agroecologia Integrado ao Ensino Médio dos Povos Indígenas do Sudeste Paraense.

IFPA/CRMB. (2013). Relatório de Tempo Aldeia do Curso Técnico em Agroecologia Integrado ao Ensino Médio dos Povos Indígenas do Sudeste Paraense.

Lander, E. (Org.). (2005) A colonialidade do saber: eurocentrismo e ciências sociais: perspectivas latino-americanas. Buenos Aires: CLACSO.

Laraia, R., \& Damatta, R. (1967). Índios e castanheiros: a empresa extrativa e os índios no médio Tocantins. São Paulo: Difusão Europeia do Livro.

Mignolo, W. D. (2003). Histórias locais/ projetos globais: colonialidade, saberes subalternos e pensamento liminar. Belo Horizonte: Ed. UFMG.

(2008). Desobediência epistêmica: a opção descolonial e o significado de identidade em política. Cadernos de Letras da UFF. Dossiê: Literatura, língua $e$ identidade, 34, 287-324.

Quijano, A. (1997). Colonialidad del poder, cultura y conocimiento en América Latina. Anuário Mariateguiano, 9(9).

Santos, B. S. (2005). Para um novo senso comum: a ciência, o direito e a política na transição paradigmática. São Paulo: Cortez. 
(2010). Descolonizar el saber,

reinventar el poder. Montevideo:

Ediciones Trilce.

Silva, L. (1912). As experiências de jovens do Campo: alternância ou alternâncias? Curitiba.

Stuani, G. M. A. (2010). Construção Curricular Crítica no Ensino de Ciências Naturais e suas implicações na prática docente. (Dissertação de Mestrado) Universidade Federal de Santa Catarina, Florianópolis.

Recebido em: 22/08/2017

Aprovado em: 02/09/2017

Publicado em: 15/12/2017

Como citar este artigo / How to cite this article / Como citar este artículo:

APA:

Ribeiro Júnior, R., Sena, L. R., \& Araújo, W. B. S. (2018). O tempo aldeia: construindo uma nova prática pedagógica. Rev. Bras. Educ. Camp., 3(1), 57-75.

ABNT:

RIBEIRO JÚNIOR, R. R.; SENA, L. R.; ARAÚJO, W. B. S. O tempo aldeia: construindo uma nova prática pedagógica. Rev. Bras. Educ. Camp., Tocantinópolis, v. 3, n. 1, p. 57-75, 2018.

\section{ORCID}

Ribamar Ribeiro Júnior

http://orcid.org/0000-0002-5859-0408

Laécio Rocha de Sena

http://orcid.org/0000-0003-2275-1051

William Bruno Silva Araújo

D http://orcid.org/0000-0002-8988-0926

\begin{tabular}{|l|l|l|l|l|l|l|l|}
\hline Rev. Bras. Educ. Camp. & Tocantinópolis & v. 3 & n. 1 & p. $57-75$ & jan./abr. & 2018 & ISSN: 2525-4863 \\
\hline
\end{tabular}

